R. J. Cohen and W. T. Sullivan, III, eds.

\title{
Local and National Regulations on Light Pollution in Italy
}

\author{
Valentina Zitelli \\ Osservatorio Astronomico di Bologna, Via Ranzani 1, 40127 Bologna, \\ Italy \\ Mario Di Sora \\ Osservatorio di Campo Catino Guarcino, Italy
}

Federico Ferrini

Dip. Fisica, Univ. di Pisa- sez. Astronomia e Astrofisica, P. Torricelli 2-56126 PISA, Italy

\begin{abstract}
The situation in terms of regulation of light pollution in Italy is here presented. The activity, started with the effort of amateur astronomers, lighting engineers and professional astronomers, is split into several actions oriented both to the local and national levels. One of the first goals was an ordinance of the city of Frosinone providing specific guidelines for lighting. The provinces of Valle d'Aosta and Veneto have followed up with local laws. The regional law of Valle d'Aosta includes a safeguard for nocturnal fauna from light pollution. The regional law of Veneto includes protection of the environment, observatories and astronomical sites. To avoid a proliferation of local laws, a national Italian bill was submitted and it is still under discussion. Bill No. 751 has been approved by the general assembly of the Italian Astronomical Society and provides more specific guidelines and standards concerning lighting in order to avoid unnecessary upward illumination and to reduce glare. At the same time a new technical standard, UNI 10819, has been settled after long debate among UNI (Italian National Standards Institute), the Italian Astronomical Society's Light Pollution Committee, lighting engineers and representatives of lighting manufacturers.
\end{abstract}

\section{Introduction}

It is unquestionable that the shift of our old economy, mostly based on agriculture, to one based primarily on products of industry has improved our standard of living, but it is also unquestionable that, as consequence, we lost our sensitivity to the ambient environment. We are not yet able to know, and to control, the environmental impact arising in each industrial production cycle.

Following the definition of positive development expressed by the World Committee on the Environment (W.C.E.D.) in 1987 as a development able to satisfy the requirements of today without compromising the possibility for future 
generations to satisfy their requirements, we need to insert the effects of urban lighting on night sky brightness as a man-made product that we must reduce before the future generation completely loses their view of the sky, and with it an important contact with our nature.

Several studies have been conducted (Walker 1970, 1973; Bertiau de Graeve and Treanor 1973) to verify the assumption that the total light emitted by a city is proportional to its population. Models have been constructed to allow calculation of the night sky brightness produced by cities at their centres and outskirts, obtaining the correlation between artificial lighting and sky brightness and population (Berry 1976), number of lumens used for street lighting and distance from the city centre (Garstang 1986). The most important observatories are carrying on long term campaigns to determine the total natural sky background, as well as monitor the level of sky pollution from artificial lights (Walker 1988, Mattila 1996, Cinzano 2000).

There are solutions to reduce this pollution of the night sky and in the following we describe actions in Italy to reduce it or at least bring the situation under control.

\section{The Italian Economy}

Nowadays 56 million people live in Italy, prevalently distributed near the most important cities, near the Po and Arno Valleys and along the $10000 \mathrm{~km}$ of coasts. Economic development and a steadily improving standard of living has produced an increase in the consumption of electrical energy and power for both public and private uses. The Italian electric company has measured over the past years $5 \%$ annual increase of the per capita amount of energy consumption used for urban lighting (Cinzano 1997). Another consequence of growth has been the expansion of urban areas. In most of the major Italian cities the darkness of the night sky is jeopardized. Because of the narrow shape of Italy, the dazzle shining up from urban areas also reaches small towns far from the emitting sources. Sky vision is thus diminished even for people living in small towns and in rural areas. Activities of amateur astronomers, often observing close to urban areas, are seriously jeopardized, but the situation is also at risk for professional astronomers, whose telescopes in effect have reduced equivalent collecting areas.

SAIt (Italian Astronomical Society), understanding the danger not only for astronomy but also for the loss of this natural heritage, promoted a committee to study and control the situation of the light pollution in Italy. At the same time SAIt members started several actions, suggesting ordinances and laws to both local and national authorities. A number of educational activities have also been organized.

\section{Actions}

The first Italian activity, in 1990 at the SAIt meeting held in Padova, was the appointment of a specific Committee to study the phenomenon of "light pollution" and to find some solutions to reduce it. In the same year a large opinion movement grew up, with the participation of professional astronomers, amateur astronomers, ecologists, politicians, lighting technicians and also some ordinary 
citizens. Local ordinances were submitted to several local governements. All the ordinances were aimed at the limitation of upward light to reduce one of the main contributions to the sky background and gave guidelines for the design, construction, operation and maintenance of lighting installations.

\subsection{National Bill}

On a national scale, to avoid proliferation of local laws that might introduce some difficulties for people and governments, in the past legistlature the Italian Parliament was presented with a national law still at the centre of political and technical-scientific debate. Bill No. 751, written by the SAIt Committee for the "Study of light pollution" with the help of lighting engineers, had been first approved in an SAIt general assembly.

The proposed law provides specific guidelines and standards concerning lighting in order to avoid unnecessary upward illumination and to reduce glare. In particular:

- it intends to limit the phenomenon sky pollution over the entire nation.

- it provides for reduction of the luminous flux when traffic on the roads is reduced (i.e. night time)

The Bill requires the following technical parameters for lighting installations:

1. Road lighting: cut-off fixtures with emission not exceeding $0 \mathrm{~cd} / \mathrm{klm}$ above $90^{\circ}$

2. Ornamental and open lighting: fixtures with emission less than $15 \mathrm{~cd} / \mathrm{klm}$ above $90^{\circ}$

3. Lighting of large areas: system fixtures with emission less than $10 \mathrm{~cd} / \mathrm{klm}$ above $90^{\circ}$

4. Monumental and building lighting: it is forbidden to illuminate in an upward direction. When it is not possible to observe this prescription, it is necessary to limit the light flux to within the outline of the concerned building

5. Luminous signs and banners:

(a) signs necessary for nocturnal activities (i.e. hotels, hospitals or police): can be lit during the night

(b) other signs: must be turned off at $11 \mathrm{pm}$ during winter time and at $00 \mathrm{pm}$ during summer time

6. It is forbidden to use rotating or fixed searchlight-type beams for advertising purposes. 


\subsection{Regional Laws}

In Italy there are several Provinces, mostly located at the borders of our country, that have a special status with local law. Among them, the Veneto Region and Valle d'Aosta have approved a law on light pollution. Veneto regional law No. 22 of June 1997 declared among its purposes the protection of the environment, observatories and astronomical sites. Valle d'Aosta law No. 17 of April 1998 expands the benefit of reduced sky pollution by including among its goals the safeguard of nocturnal fauna. Valle d'Aosta also introduced the concept of sky view as a common inheritance of all the people and not only limited to astronomers. In addition, Piemonte and Toscana have draft Bills.

\subsection{Local Activities}

Presently in Italy there are some tens of ordinances among Communal Regulations, Provincial Regulations and Prefectorial Circulars. In general in all texts is indicated the permitted upward flux emitted by lighting installations. Most of these Ordinances were approved after presentation of the results of long monitoring of the local sky by the writer of the proposed law. The Frosinone Ordinance was the first regulation applied to a city and has served as an important template that opened the way to other cities.

\subsection{Technical Standards}

The SAIt made a strong effort to match requirements of astronomers, lighting engineers and lighting manufacturers. A working group composed of the SAIt Committe and UNI (Italian National Standard Institute) representatives, after two years of long debate, settled in the spring of 1999 on the technical standard UNI 10819. This standard regards light and lighting, is available only for outdoor new lighting installations and for renewing the existent. UNI 10819 serves as a support to each national or regional law, defines the technical requirements of lighting installations, defines restrictions regarding the maximum upward flux emitted by the total lighting devices of the community to limit the upward scattered luminous flux.

The UNI standard classifies lighting installations in 5 classes:

- A - installation in a highly protected zone

- B - recreational activities lighting

- C - environmental and architectural lighting

- D - display lighting

- E - temporary lighting, such as luminaires for Christmas displays

It divides the national territory into three zones, characterized by the degree of sky protection:

- Zone 1 - Highly protected

- Zone 2 - Less protected, either by itself or as an annulus around Zone 1 
- Zone 3 - Other

The standard specifies

(a) the requirements to reduce the luminance during the night, for instance introducing the idea of road declassification when traffic is reduced,

(b) technical conditions on the construction, installation and maintenance of lighting equipment, and

(c) parameters for town lighting plans to avoid uncontrolled road lighting.

Table 1 shows the values of maximum permitted flux, $R_{n}$, published in the standard UNI 10819 for each defined class of lighting installation and for each defined Zone. $R_{n}$ is defined as the ratio between the nominal upward flux emitted from the lighting equipment and the total luminous flux. Although this standard does not undo light pollution, it permits control of lighting equipment and improves the quality of the installations.

Table 1. Maximum permitted values of upward flux (\%)

\begin{tabular}{|l|c|c|r|}
\hline Installation & Zone 1 & Zone 2 & Zone 3 \\
\hline A & & & \\
B & 1 & 5 & 10 \\
D & & & \\
\hline E & not allowed & not allowed & allowed \\
\hline
\end{tabular}

Moreover, by not defining specific components but only specific requirements, it does not limit technical developments in this field.

\subsection{Education}

Major efforts are being addressed to educational activities oriented to the people, government and light engineers. Events such as "The day of the off light" (a day without lighting) or "The star parks" (permanently protected sites for viewing the night sky) are promoted. Seminars and meetings are also devoted to the public and to specialists on lighting. At the end of 1998 a national meeting on "Technology and environment in the next century" was held in Italy. In this meeting, for the first time, light pollution was put at the same level as the other pollutions, such as noise pollution or atmospheric pollution, thanks to several actions that showed this phenomenon as another unwanted byproduct of modern technology.

All the educational activities have the purpose to explain that there is no conflict between astronomers and the activities of the public. The relationship "more light = more security" is wrong and must be substituted by the equation "better light = better security". 


\section{Conclusions}

The actions in Italy to reduce sky pollution are the following:

- Bill No. 751 presented to Italian Parliament

- The law of Regione Veneto No. 22 of 27 June 1997

- The law of Regione Valle d'Aosta No. 17 of 28 April 1998

- Draft Bills of Regione Lombardia, Piemonte and Toscana

- Several Communal ordinances

- Standard guidelines, UNI 10819

- Educational activities, conferences, books.

\section{References}

Berry R. 1976, J. Royal Astronomical Society Canada, 70, 97-115

Bertiau F. C. S. J., de Graeve E. S. J., Treanor P. J. S. J. 1973, Vatican Observatory Publ. 1, 4, 159-179

Cinzano P. 1997, Inquinamento luminoso e protezione del cielo notturno (Venezia: Istituto Veneto di Scienze, Lettere ed Arti), 224 pp. (in Italian)

Cinzano P. 2000, Mem. Soc. Astron. Italiana, 71, 159-165

Garstang R.H. 1986, PASP, 98, 364-375

Mattila K., Vaisanen P., Appen-Schnur G.F.O. 1996, Astron Astrophys. Suppl. Ser. $119,153-170$

Walker M. F. 1970, PASP, 82, 672

Walker M.F. 1973, PASP, 85, 508

Walker M. F. 1988, PASP, 100, 496 